The method of drawing these contours from the ordinary contoured map is fully described. One obvious disadvantage is that they give a dark map, but this might be overcome by drawing the contours in grey or buff. The finished map certainly gives a striking picture of relief where the slopes are steep.

\section{Sugar Cane Research}

THE Report of the proceedings of the Imperial Sugar Cane Research Conference, held in London in July 1931 , has recently been issued by H.M. Stationery Office (price 2s. 6d. net). The conference, to which reference has already been made in NATURE (July 25, p. 160) was convened by the Empire Marketing Board to discuss the future of scientific research in sugar cane production, but it was decided that the world economic position should be considered in drawing up a research programme. As a result, some seventy pages of the report give a review of the economic position of the industry, which contains many valuable facts and figures. The present organisation of research within the British Empire is considered in some detail in reference to the various cane sugar growing areas, after a brief general introduction by Dr. P. S. Hudson that deals mainly with the genetical side of the problem. Dr. Hudson concludes that whilst some early advances have been made, and still may be expected, the full utilisation of scientific methods in breeding, which involves a cytological study of the genetical material, can alone lead to continued progress and development in this line of work, which is of so much importance in developing Empire resources. Dr. W. R. Thompson points out that, owing to the wide range of habitat in which sugar cane can be successfully grown, it suffers from an unusually large list of insect parasites. With some of these, such as the leaf froghopper in Hawaii, a very great measure of success in combating them has been obtained by using the method of biological control. Dr. Thompson states that the method of biological control has this great advantage that, when it can be successfully applied, it provides what is practically permanent relief at a relatively small initial cost.

\section{Evaluating Periodicities by Machinery}

THE application of Fourier's harmonic analysis to weather phenomena has revealed many outstanding periodicities. To those who feel that the next step should be directed towards understanding the cause of these periodicities, rather than the evaluation of yet more, the invention of mechanical aids to 'periodicity hunting', such as Abbot's periodometer, will naturally make little appeal (Smithsonian Miscell. Coll., vol. 87, No. 4 (Pub. 3138): "The Periodometer, an Instrument for Finding and Evaluating Periodicities in Long Series of Observations"'. By Dr. C. G. Abbot). The device is one for avoiding numerical computation in studies of this kind. It does not detect periodicities; that has to be done by inspection of the statistical material. This step involves a personal factor. Given any suspected periodicity, the machine shows to what extent this appears consistently throughout the material, and determines the shape of the curve of variation of the element over this period. The reality of the periodicity is judged from the shape of this curve. Having decided that it is real, the operator is then able, with the aid of the machine, to eliminate this periodic variation, and so gets a residual curve that is scrutinised afresh for other periodicities. The curve of variation may depart widely from a simple sine curve, and this method of analysis therefore differs from the classical Fourier process, and on account of the presence of the personal factor will give different results when different workers use the same material. The ultimate test of merit is, of course, whether the method will lead to greater knowledge of underlying physical causes, and it remains to be seen whether this will be the case. The cost of production of the first periodometer was apparently a thousand dollars, the money being provided by the Research Corporation of New York.

\section{Chemistry and Action of Drugs}

IN his Lane Lectures on pharmacology, Prof. W. Straub, of Munich, discusses certain problems of general interest in the chemistry, synthesis, and action of drugs (Stanford University Publications : University Series: Medical Sciences, vol. 3, No. 1, 1931 ; London: Humphrey Milford). Two are devoted to digitalis, the chemistry of the glucosides of the leaf and their physiological action being reviewed. Prof. Straub points out that the differences in action of the glucosides of the cardiac tonies, digitalis, strophanthus, and squill, can be explained to a great extent by a knowledge of the speed with which they are taken up by the tissues of the body as well as by the heart, and of the ease or difficulty with which they can be afterwards destroyed. The greater response of the pathological, as compared with the normal, heart to digitalis can be similarly explained, since the slowing of the circulation permits of a greater $a b$. sorption of the drug by the tissues. These lectures were primarily addressed to pharmacologists. Three subjects were chosen as of interest to students and physicians; anæsthesia, the pharmacology of the heavy metals, and the camphor problem. In the latter lecture Prof. Straub discusses the attempts made to prepare a synthetic compound having similar stimulant effects to camphor on a failing heart and respiration without its disadvantage of slow absorption after injection. Cardiazole (pentamethyl. ene tetrazole) appears to fulfil the requirements best at the present time; it is more soluble in water than in oil, so that it will be rapidly absorbed, but its oil insolubility will ensure that it exerts a stimulant rather than a narcotic action on the central nervous system. The sixth lecture, addressed to a scientific audience without medical interests, dealt with certain general problems of the use of intoxicating drugs.

\section{Reconstruction of Tokyo and Yokohama}

DURING the seven years that followed the great earthquake of Sept. 1, 1923, the rebuilding of Tokyo and Yokohama was practically completed, at a cost of nearly eighty-five million pounds. M. Jean Gracy has written a full account of the renovated cities, of 